Internally, the wall finish is mainly fairface brickwork, Uxbridge Flint facing bricks being used for this purpose. Wood block flooring is extensively employed, although to reduce noise the corridors are finished in 'Korkoid'. The main entrance hall and staircase are paved in 'Travertine', and the columns in this area are faced in San Stefano and Ashburton marble.

The building is heated by means of Frenger Acoustic heated ceiling, a comparatively recent development consisting of perforated aluminium panels clipped to a continuous grid of heating pipes. The lighting throughout is by tungsten fittings, with the exception of the Classics Museum, which has fluorescent ceiling fittings and concealed tubes in the showcases.

The Departments of the Faculty of Letters are housed in the two long wings, each served by a subsidiary staircase. Nine lecture rooms are grouped in the centre block. Of these, seven are arranged to seat fifty students each, one to seat seventy-five, and one to seat a hundred. This last has a raked floor, and a projection room, which also serves the lecture room accommodating seventy-five.

In addition, on the first floor there is a fully equipped theatre with seating for 173 persons. This is approached directly from the main entrance hall and staircase. Underneath this theatre, on the ground floor, the main lavatory and cloakroom accommodation is grouped.

All the lecture rooms, and certain of the department rooms, are equipped with revolving or fixed blackboards, and in many of them a pull-down projection screen is also fitted. Special provision has been made throughout the building for the use of portable blackboards and display boards.

The two main common rooms, one for the academic staff and one for students, are located on the groundand second-floors respectively, each with kitchen facilities. The academic staff room opens on to a paved terrace.

The architects are Messrs. Easton and Robertson and the quantity surveyors, Messrs. Hamilton $\mathbf{H}$. Turner and Son. Consultants for the heating services, drainage work and landscape work are, respectively, Messrs. Donald Smith, Seymour and Rooley, Mr. Daniel Longden and Miss Mary Braendle. The builders are Taylor Woodrow Construction, Ltd.

By a triumphant combination of imagination and practical skill this quite large building sits comfortably and almost unobtrusively in its parkland setting. From every window in it there are trees and sky to be seen, and inside it there is an agreeable air of spaciousness and quiet. It succeeds in being friendly and domestic without losing dignity. The develop- ment of the Whiteknights Park estate has got off to a good start.

But, of course, this is only the first move. It has set the tone and pace, but it is really only a foretaste of the whole that is to be. The next moves promise to be no less exciting and no less arduous. Plans are well advanced for the two next buildings. They are to be a Hall of Residence and the Department of Physics.

It is natural that, in Reading especially, a new Hall of Residence should stand high on the priority list. On grounds of policy and of practical need, Reading has from the first developed the residential system as one of its distinguishing characteristics, and additional residential accommodation was a serious need even before the latest demands for expansion were made.

A new building for the Department of Physics is an equally urgent need. For many years the Department has conducted its multifarious activities on two separate sites, and the consequent waste of time and energy has for long been almost intolerable. To concentrate the Department in a new building in Whiteknights Park will ease this strain considerably, and will also be an important step towards removing one of the serious obstacles to an increased output of scientists and technologists.

Some time soon, the Library will have to move. Distances may not be great, but there is something rather startling in having a Faculty of Letters in one place and the University Library three-quarters of a mile away. The sudden bright thought of the lecturer, the immediate necessity for checking a reference, and, especially, the fostering of the habit of meditative reading, all demand that the gap in space between the student and the main body of his tools must be bridged as soon as can possibly be.

Other Departments of the Faculty of Science stand high in the queue. The Department of Geology is one, encouraged by handsome benefactions from the oil industry, to assist in the development of studies in sedimentology. Zoology and Microbiology, too, need much more space than is available on the London Road site if they are to make their proper contribution to national needs and to provide the required teaching for the Faculty of Agriculture.

So there will be no peace for the planners for many years yet. The heartening elements in the situation are the liveliness and enterprise of the Departments concerned, the understanding and concern of the University Grants Committe and the sensitive imagination of the architects. How long it will be before the whole of the University is safely housed in Whiteknights Park nobody can possibly know. But the move has begun, and hopes are high.

\title{
OBITUARIES
}

\section{Prof. K. F. Bonhoeffer}

THE death of Karl Friedrich Bonhoeffer on May 15 at the age of fifty-eight deprived Germany of her foremost physical chemist. He was a member of $a_{0}$ distinguished family: his father was professor of psychiatry at Berlin; his brother, who died some years ago, shared with Niemöller the lasting fame which came to those who championed the cause of the Church under Nazi tyranny. He served in the infantry in the First World War and was wounded in 1918. He suffered much also during the Second World War in another way.

Bonhoeffer's academic career began at the Universities of Tübingen and Berlin, where he graduated under Nernst and later became for seven years Haber's assistant at the Kaiser Wilhelm Institute in Dahlem. He successively occupied the chairs of physical chemistry at the Universities of Frankfurtam-Main (1930), Leipzig (1934) and Berlin (1947), where he was also a director of the Kaiser Wilhelm 
Institute for Physical Chemistry. From 1949 onwards he was director of the Max.Planck Physicochemical Institute at Göttingen.

His first researches were in photochemistry, and the "Grundlagen der Photochemie" (1933), which he wrote with Harteck, is one of the best monographs on that subject. The most widely known example of his application of spectroscopy to physicochemical problems is his investigation of the thermal dissociation of water vapour into hydrogen molecules and hydroxyl radicals, the presence of which was detected and the concentration of which was determined spectrometrically. His estimate of $103 \cdot 3 \mathrm{kcal}$. per mole as the energy of atomization of hydroxyl remains unchallenged after thirty years. Free radicals have long been recognized as intermediaries in gas reactions. It is one thing, however, to postulate their existence in order to derive a kinetic law or to explain the course of reaction, and quite another to demonstrate the existence and to measure the concentration of a specific free radical. Within recent years many experimentalists have decided to follow Bonhoeffer's example.

Bonhoeffer's most spectacular scientific achievement came in 1929, when he isolated para-hydrogen. This proved to be a crucial experiment, to be followed by rapid developments of the quantum theory of chemistry.

Eucken had in 1912 obtained highly anomalous rotational heat capacities for ordinary hydrogen gas, and Mecke in 1924 had recorded a curious alternation of intensities in the spectra of molecular hydrogen. The interpretation of these two apparently disconnected phenomena was given independently in 1927 by Dennison, Heisenberg and Hund, according to whom ordinary hydrogen, hitherto regarded as a pure substance, was in fact a 3:1 mixture of orthohydrogen and para-hydrogen, which differed from each other in their nuclear spins and in the rotational energy-levels accessible to them. Physical chemists, while not unimpressed by mathematical arguments based on symmetry properties of wave functions, remained, on the whole, sceptical, and would scarcely have accepted the quantal interpretation were hydrogen gas to remain an inseparable mixture. In 1929, Bonhoeffer and Harteck showed that at low temperatures in the presence of charcoal the conversion of ortho-hydrogen to para-hydrogen was almost complete. They obtained a sample which was 99.7 per cent pure para-hydrogen. Its vapour pressure at the triple point was found to be $2.1 \mathrm{~mm}$. higher than that of ordinary hydrogen and its boiling point $0.13^{\circ}$ lower. His pupils, A. and L. Farkas, showed that the ordinarily forbidden interconversion of ortho- and para-hydrogen could be effected catalytically by paramagnetic molecules or radicals or by atomic exchange, and the reaction $\mathrm{H}+p \cdot \mathrm{H}_{\mathbf{2}}=$ $o . \mathrm{H}_{2}+\mathrm{H}$ has proved to be the simplest of known chemical changes, now understood to the last detail.

Bonhoeffer and his school at Frankfurt-am-Main were among the first in the field with experiments on pure deuterium. He was generous with the $9 \cdot 5-\mathrm{gm}$. sample of pure heavy water which his department had produced by the spring of 1934. Having schooled his own team to be satisfied with $100 \mathrm{mgm}$. each, to be recovered after their micro-work, he lavishly sent 1-gm. samples all over the world. It was from him that Rutherford obtained his first sample.

By 1935 it was clear that Bonhoeffer's interests were moving slowly away from physical chemistry to biology ; papers appeared on deuterium in growing organisms, on the enzymic hydrolysis of glycosides in heavy water, and on the synthesis of polysaccharides in yeast cells. From 1941 onwards Bonhoeffer's principal experimental work dealt with membrane potentials and with the activation of passive iron as a physicochemical model of nerve excitation.

About half his publications appeared in the Zeitschrift für physikalische Chemie, of which he was editor with Bodenstein, Drucker and Simon from 1933 until his resignation in 1941. He was a founder editor of the new series of that journal which was issued in 1954 .

Despite his tribulations, K. F. Bonhoeffer preserved an essentially sunny disposition, sustained by a supremely happy home life with his wife, daughter and three sons. He could relax, forget chemistry, enjoy music, and dance well. In his work, he had the enthusiasm of a boy and a gift for inspiring young men. Above all, he was blessed with the humility which is the hall-mark of greatness.

\section{E. A. Moelwyn-Hughes}

\section{Dr. Otto Böhm}

Bx the death of Dr. Otto Böhm on May 17, at the age of seventy-two, the Royal Naval Scientific Service has lost a distinguished and devoted servant.

$\mathrm{He}$ was born at Zaborze in Upper Silesia on July 2,1884 , and graduated in power engineering at Berlin, proceeding later to his doctorate at Darmstadt with a thesis on the effects of transients in highvoltage power lines. Joining the Telefunken Co., where his interests moved towards electromagnetic theory and radio, he rose rapidly to become director of research in 1922. In these years he made a number of original contributions to research on radio aerials, among them being the 'Tannenbaum' element so frequently used as a component of broadside arrays for high-frequency communications. It was with the Telefunken Co., also, that he did pioneer work on the reflexion of radio waves from obstacles.

But he was a Jew, unobtrusively proud of the accomplishments of his ancient race and inimical to the rising tide of Nazi doctrine. When eventually he stood in peril, the Telefunken Co. gave him due warning and provided an escort to Switzerland.

In 1936 Böhm came to England, and in 1941 to H.M. Signal School (now Admiralty Signal and Radar Establishment). The first experimental $10-\mathrm{cm}$. radars were then being made in the laboratories for naval use, and there followed an intensely productive period in which he originated one micro-wave aerial after another. At this time his invention of the 'cheese' aerial, to give a fan-shaped beam, was outstandingly apposite to the ship-borne radar problem. This was all pioneer work in a new field of applied science with no well-documented literature to show the way, and within a few weeks of their conception some of these aerials played vital parts in dramatic incidents both at sea and in coastal defence. To this work he brought a rare and remarkable combination of engineering design knowledge allied with an ability to go really deeply into the mathematical theory of aerial design.

His full-time service with the Establishment ended in 1946 , but he continued as a consultant until his death, working as hard as ever and visiting the Establishment several times a month. His originality sparkled until the end, and in his last year he put forward a new approach to the problem of supergain 